\title{
Cisplatin-Topotecan Regimen
}

National Cancer Institute

\section{Source}

National Cancer Institute. Cisplatin-Topotecan Regimen. NCI Thesaurus. Code C65071.

A regimen consisting of cisplatin and topotecan used for the treatment of advancedstage and recurrent cervical cancer. 